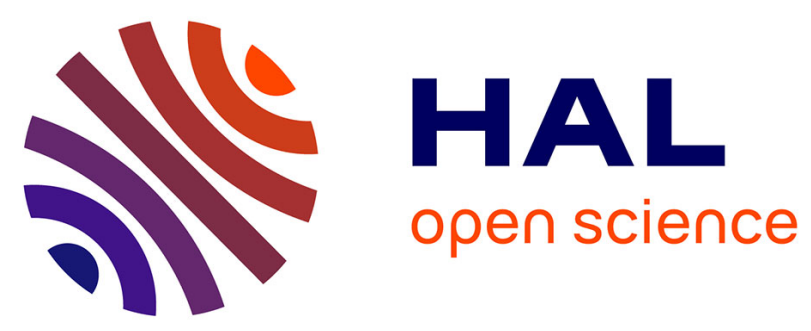

\title{
Hydrogen peroxide produced by NADPH oxidases increases proline accumulation during salt or mannitol stress in Arabidopsis thaliana
}

Kilani Ben Rejeb, Delphine Lefebvre-de Vos, Isabel Le Disquet, Anne-Sophie Leprince, Marianne Bordenave, Régis Maldiney, Asma Jdey, Chedly Abdelly, Arnould Savouré

\section{To cite this version:}

Kilani Ben Rejeb, Delphine Lefebvre-de Vos, Isabel Le Disquet, Anne-Sophie Leprince, Marianne Bordenave, et al.. Hydrogen peroxide produced by NADPH oxidases increases proline accumulation during salt or mannitol stress in Arabidopsis thaliana. New Phytologist, 2015, 208 (4), pp.1138-1148. 10.1111/nph.13550 . hal-01187624

\section{HAL Id: hal-01187624 https://hal.sorbonne-universite.fr/hal-01187624}

Submitted on 27 Aug 2015

HAL is a multi-disciplinary open access archive for the deposit and dissemination of scientific research documents, whether they are published or not. The documents may come from teaching and research institutions in France or abroad, or from public or private research centers.
L'archive ouverte pluridisciplinaire HAL, est destinée au dépôt et à la diffusion de documents scientifiques de niveau recherche, publiés ou non, émanant des établissements d'enseignement et de recherche français ou étrangers, des laboratoires publics ou privés. 
1 Hydrogen peroxide produced by NADPH oxidases increases proline accumulation

2

3

4 Kilani Ben Rejeb ${ }^{1,2}$, Delphine Lefebvre-De Vos ${ }^{1}$, Isabel Le Disquet ${ }^{1}$, Anne-Sophie Leprince ${ }^{1}$,

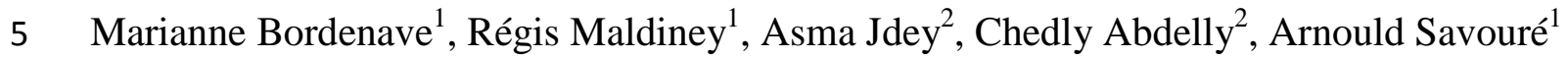

6 during salt or mannitol stress in Arabidopsis thaliana

${ }^{1}$ Sorbonne Universités, UPMC Univ Paris 06, Adaptation des Plantes aux Contraintes Environnementales, Case 156, 4 place Jussieu, F-75005, Paris, France ; ${ }^{2}$ Laboratoire des Plantes Extrêmophiles, Centre de Biotechnologie de Borj-Cedria (CBBC), BP 901, HammamLif, 2050, Tunisia.

*Corresponding author:

Arnould Savouré, email: arnould.savoure@upmc.fr

Phone: +33 (0)1 442726 72, Fax: +33 (0)1 44276151

\begin{tabular}{|l|l|l|l|}
\hline $\begin{array}{l}\text { Total word count (excluding summary, } \\
\text { references and legends): }\end{array}$ & 5307 & No. of figures: & $\dot{8}$ (Fig 2 in colour) \\
\hline Summary: & 198 & No. of Tables: & $\dot{0}$ \\
\hline Introduction: & 1069 & $\begin{array}{l}\text { No of Supporting } \\
\text { Information files: }\end{array}$ & 5 (Fig. S1-S4; Table S1) \\
\hline Materials and Methods: & 1239 & &. \\
\hline Results: & 1427 & &. \\
\hline Discussion: & 1468 & & \\
\hline Acknowledgements: & 103 & & \\
\hline
\end{tabular}




\section{Summary}

- Many plants accumulate proline, a compatible osmolyte, in response to various environmental stresses such as water deficit and salinity. In some stress responses, plants generate hydrogen peroxide $\left(\mathrm{H}_{2} \mathrm{O}_{2}\right)$ that mediates numerous physiological and biochemical processes. The aim was to study the relationship between stress-induced proline accumulation and $\mathrm{H}_{2} \mathrm{O}_{2}$ production.

- Using pharmacological and reverse genetic approaches, the role of NADPH oxidases (Rboh) in the induction of proline accumulation was investigated in Arabidopsis thaliana in response to stress induced by either $200 \mathrm{mM} \mathrm{NaCl}$ or $400 \mathrm{mM}$ mannitol.

- Stress from $\mathrm{NaCl}$ or mannitol resulted in a transient increase in $\mathrm{H}_{2} \mathrm{O}_{2}$ content accompanied by accumulation of proline. Dimethylthiourea, a scavenger of $\mathrm{H}_{2} \mathrm{O}_{2}$, and diphenylene iodonium (DPI), an inhibitor of $\mathrm{H}_{2} \mathrm{O}_{2}$ production by NADPH oxidase, were found to significantly inhibit proline accumulation in these stress conditions. DPI also reduced the expression level of $\Delta^{1}$-pyrroline-5-carboxylate synthetase, the key enzyme involved in the biosynthesis of proline. Similarly less proline accumulated in KO-mutants lacking either AtRbohD or AtRbohF than in wild type in response to the same stresses.

- Our data demonstrate that AtRbohs contribute to $\mathrm{H}_{2} \mathrm{O}_{2}$ production in response to $\mathrm{NaCl}$ or mannitol stress to increase proline accumulation in A. thaliana.

Key-words: Abiotic stresses; Arabidopsis thaliana; cell signalling; hydrogen peroxide; NADPH-oxidases (Rboh); proline metabolism. 


\section{Introduction}

In their natural environments, plants commonly encounter a variety of abiotic constraints like drought and salinity (Nakashima et al., 2009). To overcome these constraints, plants have developed a variety of adaptive mechanisms that allow them to perceive external signals and to optimize adaptive responses. One of these mechanisms is osmotic adjustment through the accumulation of large quantities of osmolytes as it allows plants to avoid water deficit stress by maintaining water uptake. Glycine betaine, polyols, sugars and free amino acids are examples of such osmolytes (Chen \& Jiang, 2010; Slama et al., 2015).

Proline is the most common free amino acid to accumulate in plants subjected to water deficit stress. Proline has multifunctional roles though which do not necessarily relate to the osmotic balance (for review see Szabados \& Savouré, 2010). Proline may stabilize protein complexes, scavenge free radicals and be a source of carbon and nitrogen for growth after stress relief. Proline biosynthesis and degradation are involved in regulating intracellular redox potential and storage as well as the transfer of energy and reducing power (Sharma et al., 2011; Szabados \& Savouré, 2010). The beneficial effect of proline on plant growth after stress is likely to be the result of changes in proline metabolism rather than the accumulation of the amino acid itself (Sharma et al., 2011; Szabados \& Savouré, 2010).

The proline content of plant cells depends on tight regulation of its proline biosynthesis and catabolism. Housekeeping levels of proline biosynthesis occur in the cytosol, but stress-induced biosynthesis is thought to be localized in chloroplasts (Székely et al., 2008). When under water-deficit stress, proline is mainly synthesized from glutamate. The bifunctional pyrroline-5-carboxylate synthetase (P5CS) reduces glutamate to glutamyl-5semialdehyde, which is spontaneously converted to pyrroline-5-carboxylate (P5C). P5C is then reduced to proline by P5C reductase (P5CR). Degradation of proline takes place in mitochondria via the sequential action of proline dehydrogenase (ProDH) and P5C dehydrogenase. The rate-limiting steps in proline biosynthesis and degradation are catalyzed by P5CS and ProDH, respectively. Two closely related P5CS-encoding genes were identified in Arabidopsis thaliana. P5CS1 is induced by drought and salt stress (Savouré et al., 1995; Yoshiba et al., 1995), while P5CS2 is expressed in dividing cells in cell suspension cultures (Strizhov et al., 1997), in meristematic and reproductive tissues (Székely et al., 2008), and in response to biotic stress such as incompatible plant-pathogen interactions (Fabro et al., 2004). Similarly, A. thaliana has two genes for ProDH, ProDH1 and ProDH2 (Kiyosue et al., 1996; Verbruggen et al., 1996; Funck et al., 2010). ProDH1 is thought to encode the main isoform 
involved in proline degradation (for review see Servet et al., 2012). The expression of ProDH1 is down-regulated by osmotic stress and upregulated by proline (Kiyosue et al., 1996; Verbruggen et al., 1996).

The regulation of P5CS and ProDH expression has been studied to identify components of signalling pathways that control proline accumulation. Under non-stress conditions, phospholipase $\mathrm{D}$ functions as a negative regulator of proline biosynthesis in Arabidopsis (Thiery et al., 2004), whereas calcium signalling and phospholipase C (PLC) trigger P5CS1 transcription and proline accumulation during salt stress (Parre et al., 2007). P5CS1 expression has also been found to be stimulated by light (Hayashi et al., 2000) and nitric oxide (Zhao et al., 2009) and it is abscisic acid (ABA) independent under water-deficit stress (Savouré et al., 1997; Sharma \& Verslues, 2010). Recently Leprince et al. (2015) demonstrated that phosphatidylinositol 3-kinase is involved in the regulation of proline catabolism through transcriptional regulation of ProDH1.

Another common plant response to all types of environmental constraints is the accumulation of ROS, which are toxic at high concentrations but at lower concentrations may act as signal molecules in the control of various cellular processes. $\mathrm{H}_{2} \mathrm{O}_{2}$ is a ROS produced by plant plasma membrane-localized NADPH oxidases, known as respiratory burst oxidase homologues (Rbohs). Rbohs reduce molecular oxygen to superoxide by oxidising NADPH via FAD and two hemes. The superoxide primary product is then converted into $\mathrm{H}_{2} \mathrm{O}_{2}$ by superoxide dismutase (Sagi \& Fluhr, 2001; Sagi \& Fluhr, 2006). The Arabidopsis genome contains 10 NADPH oxidase-encoding genes, designated AtRbohA to $J$, that exhibit different patterns of expression throughout plant development and in response to environmental factors (Fluhr, 2009; Marino et al., 2012). For instance, AtRbohA, B and $C$ are only expressed in roots, especially in the elongation zone. AtRbohC was specifically identified as playing a role in root hair development (Foreman et al., 2003). AtRbohH and $J$ are reported to be expressed only in pollen. Both AtRbohD and AtRbohF are expressed in all plant organs and are the main isoforms involved in pathogen defence responses (Torres et al., 2002), ABA-induced stomatal closure (Kwak et al., 2003), jasmonic acid signalling regulated by transcription factor MYC2 (Maruta et al., 2011) and ROS-dependent regulation of $\mathrm{Na}^{+} / \mathrm{K}^{+}$homeostasis under salt stress (Ma et al., 2012). AtRbohD has also been demonstrated to mediate rapid systemic signalling triggered by multiple abiotic stresses (Miller et al., 2009) and to be required for salt acclimation signalling mediated by heme oxygenase in Arabidopsis (Xie et al., 2011). It was reported that mild salt stress causes a rapid and transient accumulation of ROS in A. thaliana 
(peak I after $1 \mathrm{~h}$ ) followed by a second oxidative burst (peak II after 6 h) (Xie et al., 2011). The conclusion is that HY1 heme oxygenase plays an important role in salt acclimation signalling and requires the participation of AtRbohD-derived ROS from peak II. More recently, it has been reported that AtRbohF fulfils a crucial role in protecting shoot cells from transpiration-dependent accumulation of excess $\mathrm{Na}^{+}$(Jiang et al., 2012). Rbohs are thus key regulators of ROS production with pleiotropic functions in plants.

It is possible that there is a link between quantitative changes in ROS and proline. Exogenous $\mathrm{H}_{2} \mathrm{O}_{2}$ treatment led to a significant accumulation of proline in coleoptiles and radicles of maize seedlings due to the induction of biosynthetic P5CS enzyme activity and a decrease in catabolic ProDH enzyme activity (Yang et al., 2009). Fabro et al. (2004) have also demonstrated that ROS can mediate the activation of AtP5CS2 and proline accumulation during biotic stress. However, reports on the relationship between endogenous ROS increase and proline accumulation under osmotic stress are still limited and the link between NADPH oxidases and proline accumulation has never been addressed. In the present study, the role of ROS-generating NADPH-oxidase enzymes in proline accumulation in response to salt or mannitol stress was investigated in Arabidopsis thaliana seedlings.

\section{Materials and Methods}

\section{Growth conditions and stress treatments}

Arabidopsis thaliana (L.) Heynh ecotype Columbia-0 (Col-0) was used as the wild-type in this study. Homozygous Arabidopsis thaliana transposon insertion mutant lines atrbohd-3 (European Arabidopsis Stock Centre code N9555) and atrbohf-3 (European Arabidopsis Stock Centre code N9557) and double mutant atrbohd/f (European Arabidopsis Stock Centre code N9558) (Torres et al., 2002) were ordered from the European Arabidopsis Stock Centre. Homozygous T-DNA insertion lines SALK_070610 (atrbohd; seventh exon insertion) and SALK_059888 (atrbohf; third intron insertion) were ordered from the Salk collection (Pogany et al., 2009) and used as controls for the transposon insertion lines.

Surface-sterilized seeds of wild-type (Col-0) and Arabidopsis mutant plants were sown onto grids placed on $0.5 \times$ Murashige and Skoog (MS) solid agar medium in Petri dishes according to Parre et al. (2007). After $24 \mathrm{~h}$ at $4^{\circ} \mathrm{C}$ to break dormancy, seedlings were allowed to grow at $22^{\circ} \mathrm{C}$ under continuous light ( $90 \mu \mathrm{mol}$ photons $\mathrm{m}^{-2} \mathrm{~s}^{-1}$ ). Twelve-day-old Arabidopsis seedlings were exposed to $\mathrm{H}_{2} \mathrm{O}_{2}$ (5 to $120 \mathrm{mM}$ ), paraquat (PQ, also called methyl viologen, 5 to 120 $\mu \mathrm{M}), 200 \mathrm{mM} \mathrm{NaCl}$ or $400 \mathrm{mM}$ mannitol for $24 \mathrm{~h}$. To alter ROS levels, the seedlings were 
pre-incubated for $4 \mathrm{~h}$ without or with $\mathrm{H}_{2} \mathrm{O}_{2}$ scavenger dimethylthiourea (DMTU, 5 to $40 \mathrm{mM}$ ) or flavoenzyme inhibitor diphenylene iodonium (DPI, 5 to $40 \mu \mathrm{M}$ ) in $0.5 \times$ liquid $\mathrm{MS}$ medium and then exposed to either $\mathrm{NaCl}$ or mannitol for $24 \mathrm{~h}$.

\section{Determination of ion content}

Whole plants were harvested, rinsed twice in pure water and quickly blotted. Samples were dried at $60{ }^{\circ} \mathrm{C}$ until they reached constant weight then ground. Ions were extracted from samples in $0.5 \% \mathrm{HNO}_{3} . \mathrm{Na}^{+}$and $\mathrm{K}^{+}$were assayed by flame emission photometry (Corning, UK).

\section{Proline content measurements}

Free proline content was measured according to the Bates method (Bates et al., 1973). Powdered plant samples (50 to $100 \mathrm{mg}$ ) were homogenized in $1.5 \mathrm{ml}$ of $3 \%$ sulfosalicylic acid and centrifuged at $14,000 \times \mathrm{g}$ for $10 \mathrm{~min}$ at $4{ }^{\circ} \mathrm{C}$. To $1 \mathrm{ml}$ of this extract, $1 \mathrm{ml}$ of acidninhydrin and $1 \mathrm{ml}$ of glacial acetic acid were added. The reaction mixture was incubated at $100^{\circ} \mathrm{C}$ for $1 \mathrm{~h}$ then placed on ice to stop the reaction. In the presence of proline, the reaction produces a red chromogen. The chromogen was extracted with $2 \mathrm{ml}$ of toluene and the absorbance of the resulting upper phase was read at $520 \mathrm{~nm}$. Proline content of samples was calculated by referring to a standard curve drawn from absorbance readings from samples containing known concentrations of proline.

\section{$\mathrm{H}_{2} \mathrm{O}_{2}$ content measurements}

$\mathrm{H}_{2} \mathrm{O}_{2}$ content was determined in a horseradish peroxidase-based spectrophotometric assay following the protocol described by Oracz et al. (2009). Plant samples (300 mg FW) were ground in a mortar on ice in $1 \mathrm{ml}$ of $0.2 \mathrm{M}$ perchloric acid. After $15 \mathrm{~min}$ of centrifugation at $13,000 \times g$ at $4^{\circ} \mathrm{C}$, the resulting supernatant was neutralized to $\mathrm{pH} 7.5$ with $4 \mathrm{M} \mathrm{KOH}$ and then centrifuged at $13,000 \times g$ at $4^{\circ} \mathrm{C}$. The concentration of $\mathrm{H}_{2} \mathrm{O}_{2}$ in the supernatant was immediately determined by adding peroxidase with substrates 3-dimethylaminobenzoic acid and 3-methyl-2-benzothiazolidone hydrazone. The increase in absorbance at $590 \mathrm{~nm}$ was monitored for $15 \mathrm{~min}$ after the addition of peroxidase at $25^{\circ} \mathrm{C}$ and compared to a calibration curve obtained with known amounts of fresh $\mathrm{H}_{2} \mathrm{O}_{2}$.

\section{Histochemical detection of $\mathrm{H}_{2} \mathrm{O}_{2}$}


173 The production of $\mathrm{H}_{2} \mathrm{O}_{2}$ was visualized in vivo by 2',7'-dichlorofluorescein diacetate $174\left(\mathrm{H}_{2} \mathrm{DCFDA}\right)$ or DAB staining methods. Arabidopsis roots were collected after 6-h treatments and immersed in $25 \mu \mathrm{M} \mathrm{H} \mathrm{H}_{2}$ DCFDA for $15 \mathrm{~min}$ in the dark and then washed with $20 \mathrm{mM}$ potassium phosphate buffer $\mathrm{pH}$ 6. Fluorescent signals were visualized using a Zeiss ApoTome microscope (excitation, $488 \mathrm{~nm}$; emission, $525 \mathrm{~nm}$ ). DAB staining was performed as described by Torres et al. (2002). Leaves from PQ-treated seedlings were detached and vacuum infiltrated with DAB solution $\left(1 \mathrm{mg} \mathrm{ml}^{-1} \mathrm{DAB}-\mathrm{HCl}, \mathrm{pH} 3.8\right)$. DAB forms a reddishbrown polymer in the presence of $\mathrm{H}_{2} \mathrm{O}_{2}$ formation. After staining, leaves were cleared in $96 \%$ boiling ethanol and observed using a binocular microscope. For both staining methods, digital images were obtained with an AxioCam camera and AxioVision software (Zeiss).

\section{Cytochemical detection of $\mathrm{H}_{2} \mathrm{O}_{2}$}

Cytochemical detection of $\mathrm{H}_{2} \mathrm{O}_{2}$ was carried out according to the method described by Bestwick et al. (1997). Leaf samples were collected from treated and control seedlings and incubated in freshly prepared $5 \mathrm{mM}$ cerium chloride for $30 \mathrm{~min}$. The leaves were then fixed in a solution containing $4 \%$ glutaraldehyde and $1.5 \%$ paraformaldehyde for $1 \mathrm{~h}$, post-fixed for 45 min in 1\% osmium tetroxide and then embedded in Eponaraldite resin after dehydration in an ethanol series. Sections (60 to $80 \mathrm{~nm}$ thick) were cut with a LKB 2128 ultramicrotome, mounted on uncoated copper grids, and stained with 5\% uranyl acetate. Sections were observed using a Zeiss912 Omega transmission electron microscope. Digital images were obtained using a Veleta Camera (2kx2k, Olympus) and iTem software (Zeiss).

\section{RT-PCR and qRT-PCR Analysis}

Total RNA was extracted from 100 mg of plant tissue ground in liquid nitrogen using a mixer mill (MM301, Retsch, Germany). The powder was suspended in $0.5 \mathrm{~mL}$ extraction buffer (0.2 M Tris-HCl, 0.5\% (v/v) SDS, $0.25 \mathrm{M} \mathrm{NaCl}, 25 \mathrm{mM}$ EDTA) and mixed with $0.5 \mathrm{~mL}$ of phenol/chloroform/isoamylalcohol (25:24:1, v/v/v). The aqueous phase was extracted 3 times with phenol/chloroform/isoamylalcohol. Total RNA was then precipitated overnight on ice with $2 \mathrm{M} \mathrm{LiCl}$. After centrifugation (15 min, 10,000 $\times \mathrm{x}$ g), the pellet was resuspended in $2 \mathrm{M}$ $\mathrm{LiCl}$ and left to precipitate for $6 \mathrm{~h}$ on ice. Traces of DNA were removed by DNase treatment. RNA quantified by measuring the absorbance at $260 \mathrm{~nm}$ using a Nanovue ${ }^{\circledR}$ spectrophotometer (GE Healthcare Life Science). First-strand cDNA was obtained from 1.5 
$\mu \mathrm{g}$ of total RNA using RevertAidTM reverse transcriptase synthesis kit (Fermentas) and oligo(dT)23 as primer.

For RT-PCR, cDNAs were amplified using Taq polymerase and gene-specific primers (Supporting Information Table S1). APT1 (adenine phosphoribosyltransferase 1; At1g27450) gene transcripts were amplified as a control. Amplified PCR fragments were visualized using ethidium bromide stained 2\% (w/v) agarose gels. RT-PCR signals were quantified using the ImageJ 1.48 software (National Institutes of Health, Bethesda, MD).

For quantitative PCR $5 \mu \mathrm{L}$ of diluted cDNA was used with $10 \mu \mathrm{L}$ of Maxima SYBR Green/ROX qPCR Master Mix (Fermentas, France) and gene-specific primers (Supporting Information Table S1) in a Mastercycler ${ }^{\circledR}$ ep realplex (Eppendorf, France). Critical thresholds (Ct) were calculated using the Realplex 2.0 software (Eppendorf, France). For each gene, a standard curve made with dilutions of cDNA pools was used to calculate the reaction efficiencies, and relative expressions were calculated according to Hellemans et al. (2007) with APT1 (At1g27450) and AT5G (At5g13440) as housekeeping genes. A mixture of cDNAs corresponding to each sample was used as reference. All qRT-PCR experiments were carried out with three biological replicates.

\section{Western blots}

Total proteins were subjected to SDS-PAGE using 8\% acrylamide resolving gels and electroblotted onto a PVDF membrane. Rabbit polyclonal antibodies raised against P5CS or ProDH were used as primary antibodies (Thierry et al., 2004; Parre et al., 2007). Blots were incubated with secondary horseradish peroxidase-conjugated antibodies (GE Healthcare Life Sciences). The highly sensitive ECL Prime detection system (GE Healthcare) was used to quantify proteins using ImageJ 1.48 software (National Institutes of Health, Bethesda, MD) after densitometric scanning of autoradiography films. Alternatively the Storm 840 FluorImager (Molecular Dynamics) was used to visualise and quantify proteins on blots.

\section{Statistical analysis}

A one-way analysis of variance (ANOVA) at $P<0.05$ significance level was performed using the SPSS program for Windows. The Duncan post-hoc test was used to test significant differences between treatments. 


\section{Results}

\section{Kinetics of ROS and proline accumulation in wild-type $A$. thaliana seedlings}

To investigate ROS and proline accumulation in response to stress induced by either salt or mannitol, 12-day-old A. thaliana seedlings were exposed to $200 \mathrm{mM} \mathrm{NaCl}$ or $400 \mathrm{mM}$ mannitol for up to $24 \mathrm{~h}$. In both cases proline started to accumulate after $6 \mathrm{~h}$. A maximum 16fold increase in proline content was reached after $18 \mathrm{~h}$ of $\mathrm{NaCl}$ or mannitol stress (Fig. 1). A transient increase in $\mathrm{H}_{2} \mathrm{O}_{2}$ content was also observed in stressed seedlings after $6 \mathrm{~h} . \mathrm{H}_{2} \mathrm{O}_{2}$ content had returned to a basal level after $12 \mathrm{~h}$.

\section{Effect of $\mathrm{H}_{2} \mathrm{O}_{2}$ and paraquat on proline accumulation in A. thaliana}

The kinetics of $\mathrm{H}_{2} \mathrm{O}_{2}$ and proline accumulation in response to either $\mathrm{NaCl}$ or mannitol stress showed that proline had already started to increase $6 \mathrm{~h}$ after stress was applied when the transient increase in $\mathrm{H}_{2} \mathrm{O}_{2}$ content was also observed (Fig. 1). To determine whether $\mathrm{H}_{2} \mathrm{O}_{2}$ could be involved in proline accumulation, we first investigated whether adding different concentrations of exogenous $\mathrm{H}_{2} \mathrm{O}_{2}$ would affect proline accumulation in A. thaliana. Results showed that proline accumulation is induced by exogenous $\mathrm{H}_{2} \mathrm{O}_{2}$ application with $10 \mathrm{mM}$ $\mathrm{H}_{2} \mathrm{O}_{2}$ having the maximum effect (Fig. 2a).

Paraquat (PQ) is a herbicide which induces superoxide anions and subsequently $\mathrm{H}_{2} \mathrm{O}_{2}$ generation in situ.. Like $\mathrm{H}_{2} \mathrm{O}_{2}$, PQ also stimulated proline accumulation in Arabidopsis seedlings in a dose dependent manner with $40 \mu \mathrm{M}$ PQ having the maximum effect (Fig. 2b). Leaves treated with high concentrations of PQ such as 80 or $100 \mu \mathrm{M}$ PQ started to bleach after $48 \mathrm{~h}$ of treatment due to the high amount of $\mathrm{H}_{2} \mathrm{O}_{2}$ generated (data not shown) even though proline contents were not higher than at $40 \mu \mathrm{M}$ PQ. DAB staining revealing the presence of $\mathrm{H}_{2} \mathrm{O}_{2}$ in leaves demonstrates that exogenously applied PQ gives rise to $\mathrm{H}_{2} \mathrm{O}_{2}$ in situ in a dose dependent manner (Fig. 2c). Taken together, these results indicate a possible causal relationship between $\mathrm{H}_{2} \mathrm{O}_{2}$ and proline production. However, much less proline accumulated in the presence of $10 \mathrm{mM} \mathrm{H}_{2} \mathrm{O}_{2}$ (about 5 times less) or $40 \mu \mathrm{M}$ PQ (about 8 times less) than with $\mathrm{NaCl}$ or mannitol stress (Fig. 2a, 2b and Fig.1).

\section{Effect of DMTU, a chemical scavenger of $\mathrm{H}_{2} \mathrm{O}_{2}$, on proline accumulation in response to} stress.

To investigate whether the induction of proline accumulation by salt or mannitol requires $\mathrm{H}_{2} \mathrm{O}_{2}$, we treated $A$. thaliana seedlings with DMTU, a chemical trap for $\mathrm{H}_{2} \mathrm{O}_{2}$. As shown in 
Fig. 3a, addition of up to $40 \mathrm{mM}$ DMTU inhibited proline accumulation in a dose-dependent manner in seedlings treated with $\mathrm{NaCl}$ and to a lesser extent in those treated with mannitol.

\section{Subcellular localisation of $\mathrm{H}_{2} \mathrm{O}_{2}$ accumulation}

Multiple sources of $\mathrm{H}_{2} \mathrm{O}_{2}$ production inside plant cells have been described (Petrov \& Van Breusegem, 2012). To investigate the subcellular localization of $\mathrm{H}_{2} \mathrm{O}_{2}$ accumulation in leaves of A. thaliana seedlings, a cytochemical approach using cerium perhydroxide was taken (Bestwick et al., 1997). No visible cerium perhydroxide deposits were observed at the subcellular in $A$. thaliana leaves growing under normal growth conditions, indicating the absence of $\mathrm{H}_{2} \mathrm{O}_{2}$ using this detection method (Fig. 4). However, both salt and mannitol triggered $\mathrm{H}_{2} \mathrm{O}_{2}$ accumulation in cell walls of mesophyll cells. Importantly no cerium perhydroxide deposits were observed in the cytosol, chloroplasts or mitochondria indicating that no major $\mathrm{H}_{2} \mathrm{O}_{2}$ accumulation occurred in these organelles.

\section{NADPH oxidases are essential for proline accumulation in response to $\mathrm{NaCl}$ and mannitol stresses}

Stress-induced $\mathrm{H}_{2} \mathrm{O}_{2}$ accumulated in the cell wall and apoplasm. The main source of cell wall $\mathrm{H}_{2} \mathrm{O}_{2}$ is the plasma membrane-bound NADPH oxidase (Petrov \& Van Breusegem, 2012). We therefore hypothesized that NADPH oxidase activity is required for proline accumulation in response to salt and mannitol stress. We investigated this using a pharmacological approach. Treatments of $A$. thaliana seedlings with DPI, an inhibitor of flavin enzymes such as NADPH oxidases, resulted in a dose-dependent decrease of proline accumulation induced by salt and mannitol stress (Fig. 3b). Addition of various concentrations of DPI did not affect proline accumulation in seedlings growing under normal growth conditions. For further experiments we used $20 \mu \mathrm{M}$ DPI which diminished proline accumulation by approximately $60 \%$. To aid interpretation of results, the pharmaceutical toxicity of DPI was also tested in seedlings. As shown in Fig. 5, the reduction of proline accumulation caused by the addition of $20 \mu \mathrm{M}$ DPI to $\mathrm{NaCl}$ - and mannitol-treated seedlings for $24 \mathrm{~h}$ was totally reversed after washing the seedlings and putting them back in growth medium. In addition no leaf injury or lethality was observed whatever the treatment.

We monitored $\mathrm{H}_{2} \mathrm{O}_{2}$ production in root tips by adding $\mathrm{H}_{2}$ DCFDA, which reacts with $\mathrm{H}_{2} \mathrm{O}_{2}$ in living cells to produce fluorescent DCF. As observed in whole seedlings, $\mathrm{H}_{2} \mathrm{O}_{2}$ is detected in root tips $6 \mathrm{~h}$ after exposure to either $\mathrm{NaCl}$ or mannitol (Fig. 6a). In contrast $\mathrm{H}_{2} \mathrm{O}_{2}$ was not 
detected in root tips incubated with DPI prior to treatment with either $\mathrm{NaCl}$ or mannitol prevented, suggesting $\mathrm{H}_{2} \mathrm{O}_{2}$ production was inhibited.

The rate limiting steps in proline biosynthesis and degradation in Arabidopsis are catalyzed by P5CS and ProDH respectively. To further investigate the role of NADPH oxidase in proline metabolism, steady-state transcript levels of AtP5CS1 and AtProDH1 were investigated. Semi-quantitative RT-PCR analysis showed that DPI treatment significantly decreased P5CS1 transcript levels in response to salt and to a lesser extent to mannitol (Fig. 6c). Steady-state transcript levels of ProDH1 gene were not altered by DPI. Protein levels of P5CS and ProDH were also investigated by Western blot analyses. In wild-type A. thaliana plants, $200 \mathrm{mM}$ $\mathrm{NaCl}$ and $400 \mathrm{mM}$ mannitol both caused an increase in P5CS protein content compared with untreated plants (Fig. 6d). However, the increase in P5CS protein levels by salt or mannitol was markedly suppressed by pre-treating seedlings with DPI. In contrast to ProDH, whose protein levels were not affected by the different conditions, a good correlation was observed between P5CS transcript and protein levels and proline content.

\section{Proline accumulation in atrboh mutants}

If ROS produced by NADPH oxidase is involved in regulating proline accumulation due to $\mathrm{NaCl}$ and mannitol stress, then KO mutants defective in NADPH oxidase would be expected to accumulate less proline than wild type. Of the ten Arabidopsis NADPH oxidase genes identified, $A t R b o h D$ and $A t R b o h F$ are the only ones expressed in all plant organs and they are implicated in abiotic stress physiology (Fluhr, 2009; Marino et al., 2012). Atrbohd-3 and atrbohf-3 mutants were therefore selected for our study. Semi-quantitative RT-PCR using wild-type and mutant plants revealed that rbohd-3 and rbohf-3 homozygous plants contained no detectable levels of AtRbohD and AtRbohF transcripts in response to salt treatment (data not shown). In both atrbohd-3 and atrbohf-3 mutants, the transient increase in $\mathrm{H}_{2} \mathrm{O}_{2}$ levels at $6 \mathrm{~h}$ in response to $\mathrm{NaCl}$ and mannitol stresses was not as large as the wild-type increase (Fig. 7). After cerium perhydroxide staining no visible cerium perhydroxide deposits were observed in the leaves of atrbohd mutant seedlings grown under mannitol or salt stress, indicating the absence of detectable levels of $\mathrm{H}_{2} \mathrm{O}_{2}$ (Supporting Information Fig. S1).

The two NADPH oxidase-deficient atrbohd and atrbohf mutants were examined for the accumulation of proline and P5CS protein in response to either mannitol or salt stress. As expected, application of $200 \mathrm{mM} \mathrm{NaCl}$ or $400 \mathrm{mM}$ mannitol induced proline accumulation in wild-type Arabidopsis plants (Fig. 8a). Consistent with the results of DPI treatment in wild- 
type (see Fig. 6), atrbohd-3 and atrbohf-3 mutants accumulated less proline and less P5CS protein than wild-type in the presence of $200 \mathrm{mM} \mathrm{NaCl}$ (Fig. 8a, b). The results of $400 \mathrm{mM}$ mannitol treatments were similar although less pronounced (Fig. 8a, b). Similar results for proline accumulation were observed with independent alleles of atrbohd and atrbohf (T-DNA insertion lines SALK_070610 and SALK_059888 respectively) (Supporting Information Fig. S2). In the double atrbohd/f mutant proline levels reached similar levels to those in the single mutants in response to mannitol stress (Fig. 8). The amount of proline that accumulated in response to $\mathrm{NaCl}$ in the double mutant was slightly higher but was not as high as the level induced in wild type. It was noted that the decrease in proline and P5CS accumulation was less pronounced in the atrboh mutants than in seedlings treated with DPI (Fig. 5 and 6). Perhaps NADPH oxidases other than AtRbohD and AtRbohF or other sources of $\mathrm{H}_{2} \mathrm{O}_{2}$ are involved in the regulation of proline biosynthesis. To further demonstrate a role for $\mathrm{H}_{2} \mathrm{O}_{2}$, we reversed the effect of atrboh mutation by applying exogenous $\mathrm{H}_{2} \mathrm{O}_{2}$. Addition of $10 \mathrm{mM}$ $\mathrm{H}_{2} \mathrm{O}_{2}$ restored the levels of proline and P5CS protein accumulation in mannitol-treated atrbohd-3, atrbohf-3 and double atrbohd/f seedlings (Fig. 8).

\section{Discussion}

Plant stress tolerance involves diverse mechanisms such as signal perception and transduction, osmolyte accumulation, ion homeostasis, growth regulation and cellular protection from damage triggered by reactive oxygen species (ROS). It is widely accepted that $\mathrm{H}_{2} \mathrm{O}_{2}$ and other ROS are also important signalling molecules in the activation of defence genes in response to biotic stress (Foyer \& Noctor, 2009, Bartoli et al., 2012). The connection between ROS and proline in response to biotic stress has already been highlighted by Fabro et al. (2004). Nevertheless little is known about the involvement of ROS in the regulation of proline metabolism in response to abiotic stresses. The aim of our work was to evaluate the roles of $\mathrm{H}_{2} \mathrm{O}_{2}$ in the regulation of proline metabolism in response to two different abiotic stresses in A. thaliana. Our results showed that both $\mathrm{NaCl}$ and mannitol stress induced proline accumulation and a transient increase in $\mathrm{H}_{2} \mathrm{O}_{2}$ content (Fig. 1). The timing of these changes might suggest that $\mathrm{H}_{2} \mathrm{O}_{2}$ could act as a secondary messenger involved in triggering proline biosynthesis. This hypothesis is supported by the observation that treatment with $\mathrm{H}_{2} \mathrm{O}_{2}$ or PQ also promoted proline accumulation (Fig. 2). However these effects are not as strong as those caused by physiological $\mathrm{NaCl}$ or mannitol stresses. The fact that much less proline accumulated in response to $\mathrm{H}_{2} \mathrm{O}_{2}$ and PQ than to the stress conditions is in itself intriguing. 
371 One possibility is that additional signalling pathways are involved in the full stress response.

372 Phospholipase D enzymes are putative signalling components as they have been previously 373 shown to negatively regulate proline accumulation in non-stress or mild stress conditions 374 (Thiery et al., 2004). Following this reasoning, phospholipase D activity may need to be inhibited in order to elicit a full proline stress response by $\mathrm{H}_{2} \mathrm{O}_{2}$ treatment. $\mathrm{As}_{2} \mathrm{O}_{2}$ is able to increase proline accumulation and DMTU is an effective inhibitor of proline accumulation induced by $\mathrm{NaCl}$ or mannitol, our data suggest that the stress-induced proline accumulation observed in A. thaliana seedlings is mediated at least partly by $\mathrm{H}_{2} \mathrm{O}_{2}$. ROS, such as singlet oxygen $\left({ }^{1} \mathrm{O}_{2}\right), \mathrm{H}_{2} \mathrm{O}_{2}$, and hydroxyl radical $\left(\mathrm{OH}^{*}\right)$, are produced during normal aerobic metabolism in different cell compartments such as cell walls, plasma membranes, chloroplasts, mitochondria and peroxisomes (Dat et al., 2000). The production of $\mathrm{H}_{2} \mathrm{O}_{2}$ has been repeatedly demonstrated at the subcellular level by using $\mathrm{CeCl}_{3}$ techniques, for example, during abscisic acid signalling (Hu et al., 2006), pathogen attack (Bestwick et al., 1997), responses to ozone (Pellinen et al., 1999), drought (Hu et al., 2006), anoxia (Blokhina et al., 2001), and heavy metal excess (Romero-Puertas et al., 2004). Our observation based on $\mathrm{CeCl}_{3}$ detection revealed that either salt or mannitol stress induced $\mathrm{H}_{2} \mathrm{O}_{2}$ accumulation in walls of mesophyll cells (Fig. 4). $\mathrm{H}_{2}$ DCFDA fluorescence analysis also revealed an accumulation of $\mathrm{H}_{2} \mathrm{O}_{2}$ in Arabidopsis root tips in response to either $\mathrm{NaCl}$ or mannitol stress (Fig. 6). This is consistent with a report that $\mathrm{H}_{2} \mathrm{O}_{2}$ accumulation was detected along the plasma membrane of maize leaves challenged with abscisic acid and water-deficit stress (Hu et al., 2006). Using $\mathrm{CeCl}_{3}$, we did not detect any of $\mathrm{H}_{2} \mathrm{O}_{2}$ in chloroplasts or in any other organelle of $A$. thaliana leaf cells after $6 \mathrm{~h}$ of either salt or mannitol treatment. The apoplastic oxidative burst and resultant $\mathrm{H}_{2} \mathrm{O}_{2}$ accumulation in the extracellular space is characteristic of plant cells exposed to biotic and abiotic stresses (Bartoli et al., 2012). Studies of different plant species have demonstrated the action of plasma membrane-bound NADPH oxidases in the apoplastic ROS-producing system during early oxidative bursts which is critical in plant signalling and development, including in defence, root hair development, stomatal closure, and early responses to salt stress (Torres et al., 2002; Foreman et al., 2003; Kwak et al., 2003; Leshem et al., 2007). DPI is a commonly used potent inhibitor of flavin enzymes such as NADPH oxidase. We found that DPI efficiently inhibited $\mathrm{H}_{2} \mathrm{O}_{2}$ production in $A$. thaliana seedling roots exposed to $\mathrm{NaCl}$ or mannitol (Fig. 6a), strongly suggesting that at least some of the $\mathrm{H}_{2} \mathrm{O}_{2}$ production induced by salt or mannitol originates from NADPH oxidase. 
In response to either salt or mannitol stress, P5CS1 proline biosynthesis transcript and protein levels increased at the same time as proline accumulated. Pretreatment of $A$. thaliana seedling with DPI reduced the salt- or mannitol-induced proline accumulation in a dose-dependent manner (Fig. 6). In addition, DPI significantly diminished P5CS1 transcript and protein accumulation. The reaction catalyzed by NADPH oxidase uses $\mathrm{O}_{2}$ to generate superoxide $\left(\mathrm{O}_{2}{ }^{-}{ }^{-}\right)$, which is then converted into $\mathrm{H}_{2} \mathrm{O}_{2}$ by apoplastic superoxide dismutase. $\mathrm{H}_{2} \mathrm{O}_{2}$, as a nonpolar molecule, can easily pass through the plasma membrane probably through aquaporins. $\mathrm{H}_{2} \mathrm{O}_{2}$ has important roles as a signalling molecule in the regulation of a variety of biological processes. Possibly by redox changes $\mathrm{H}_{2} \mathrm{O}_{2}$ might directly or indirectly activate unknown signalling components, such as transcription factors, to regulate the transcription of proline biosynthesis genes.

The role of Rbohs in the regulation of proline metabolism was further investigated by reverse genetic approach using atrbohd and atrbohf $\mathrm{KO}$ mutants. Compared to wild type, the strong reduction of $\mathrm{H}_{2} \mathrm{O}_{2}$ production after $6 \mathrm{~h}$ in the atrbohd mutant in response to $\mathrm{NaCl}$ and mannitol, observed to a lesser extent in the atrbohf, could be considered to be consistent with AtRbohD being the most highly expressed member of the AtRboh gene family in response to salt (Leshem et al., 2007). Furthermore the cytochemical detection of $\mathrm{H}_{2} \mathrm{O}_{2}$ indicated that $\mathrm{H}_{2} \mathrm{O}_{2}$ production during salt and mannitol stress is associated with AtRbohD expression.

Our study shows that proline accumulation was 20-fold higher in salt-treated wild-type compared to control wild-type plants; however, it was respectively only 5-fold and 9-fold higher in salt-treated atrbohd and atrbohf seedlings compared to their controls. The double atrbohd/f mutant surprisingly produced slightly more proline in response to $\mathrm{NaCl}$ than the corresponding single mutants possibly because the double mutant is more sensitive to $\mathrm{NaCl}$. Similarly, a much lower P5CS level was observed in the atrbohd mutant, compared to only a marginal reduction in atrbohf mutant compared to wild-type plants. Taken together, these results indicate that these NADPH oxidase isoforms are involved in proline accumulation during salt stress with AtRbohD having a prominent role. It was noted that the decrease in proline accumulation was more pronounced in wild-type seedlings treated with DPI than in atrboh mutants. This result would implicate other NADPH oxidases in the proline accumulation response. Indeed according to qPCR measurements, AtRbohA, AtRbohB and AtRobohC transcripts are more abundant in atrbohd and atrbohf mutants than in wild-type under stress, which is possibly preliminary evidence of a feed-back mechanism in these mutants (Supporting Information Fig. S3). 
Recently, it has been demonstrated that ROS generated by AtrbohF has a specific and predominant role in regulating $\mathrm{Na}^{+}$accumulation and soil-salinity tolerance (Jiang et al., 2012). When grown in saline soil, atrbohf mutant accumulated higher levels of $\mathrm{Na}^{+}$than wildtype plants. In addition, Ma et al. (2012) have suggested that AtrbohF acts redundantly with AtrbohD in regulating $\mathrm{Na}^{+} / \mathrm{K}^{+}$homeostasis. These independent observations lead us to postulate that the difference in proline accumulation in the wild-type and atrboh mutants plants could be due to impaired $\mathrm{Na}^{+} / \mathrm{K}^{+}$regulation. No differences in $\mathrm{Na}^{+}$and $\mathrm{K}^{+}$content were found between atrbohd, atrbohf and wild-type plants subjected to $\mathrm{NaCl}$ treatment for $24 \mathrm{~h}$ (Supporting Information Fig. S4). However the double atrbohdf mutant contained less $\mathrm{Na}^{+}$ but had a higher $\mathrm{Na}^{+} / \mathrm{K}^{+}$ratio. Differences in $\mathrm{Na}^{+}$accumulation in atrboh single mutants between our study and the study of Jiang et al. (2012) were probably due to large differences in growth and stress conditions in the two experimental systems, such as continuous light versus $16 \mathrm{~h} \mathrm{light/8} \mathrm{h}$ dark cycles or short versus long durations of stress. However the regulation of proline accumulation by Rboh in Arabidopsis was probably mainly due to the osmotic stress component of salt stress rather than to the ionic component, because Rboh was involved in the response to both $\mathrm{NaCl}$ and mannitol stress. Lastly, since the generation of ROS by Rboh causes changes in the cell redox potential, we postulate that redox-sensitive signalling components or transcription factors may be activated and to influence the expression of proline biosynthesis genes.

In conclusion, our results shed new light on the regulation of proline metabolism in response to abiotic stresses showing the involvement of NADPH oxidase and $\mathrm{H}_{2} \mathrm{O}_{2}$. We show that $\mathrm{H}_{2} \mathrm{O}_{2}$ is involved in proline accumulation induced by salt and mannitol stresses. First, proline accumulation was preceded by elevated $\mathrm{H}_{2} \mathrm{O}_{2}$ levels, and scavenging of $\mathrm{H}_{2} \mathrm{O}_{2}$ by DMTU abolished proline accumulation. Second, we have presented evidence that NADPH oxidases are the potential source of the observed stress-induced $\mathrm{H}_{2} \mathrm{O}_{2}$ generation. Third, the absence of $\mathrm{H}_{2} \mathrm{O}_{2}$ production in cell walls and the accumulation of less proline in atrbohd and atrbohf $\mathrm{KO}$ mutants in response to $\mathrm{NaCl}$ and mannitol provides convincing genetic evidence that the corresponding NADPH oxidase isoforms contribute to proline accumulation.

\section{Acknowledgements}

We thank the IFR 83 Electron Microscopy Service of the CNRS Institute of Integrative Biology (UPMC, Paris, France) for use of transmission electron microscopy facilities. We 
thank Christophe Bailly for valuable scientific discussion and advice on ROS measurements and Alban Launay and Pierre Carol for critical reading of the manuscript. K. Ben Rejeb was supported by a PhD scholarship from the Tunisian Ministry of Higher Education and Scientific Research (LR10CBBC02) and the Tunisian-French CMCU (Comité Mixte de Coopération Universitaire) network (29174UF). Part of this study was supported by European Union COST program FA0901 “Putting halophytes to work - From genes to ecosystem”.

\section{References}

Bartoli CG, Casalongue C, Simontacchi M, Márquez-García B, Foyer CH. 2012. Interactions between hormone and redox signalling pathways in the control of growth and cross tolerance to stress. Environmental and Experimental Botany 94: 73-88.

Bates LS, Waldren RP, Teare ID. 1973. Rapid determination of free proline for water stress studies. Plant and Soil 39: 205-207.

Bestwick CS, Brown IR, Bennett MH, Mansfield JW. 1997. Localization of hydrogen peroxide accumulation during the hypersensitive reaction of lettuce cells to Pseudomonas syringae pv phaseolicola. Plant Cell 9: 209-221.

Blokhina OB, Chirkova TV, Fagerstedt KV. 2001. Anoxic stress leads to hydrogen peroxide formation in plant cells. Journal of Experimental Botany 52: 1-12.

Chen H, Jiang JG. 2010. Osmotic adjustment and plant adaptation to environmental changes related to drought and salinity. Dossiers environnement 18: 309-319.

Dat J, Vandenabeele S, Vranová E, Van Montagu M, Inzé D, Van Breusegem F. 2000. Dual action of the active oxygen species during plant stress responses. Cellular and Molecular Life Sciences 57: 779-795.

Fabro G, Kovács I, Pavet V, Szabados L, Alvarez ME. 2004. Proline accumulation and AtP5CS2 gene activation are induced by plant-pathogen incompatible interactions in Arabidopsis. Molecular Plant-Microbe Interactions. 17: 343-350.

Fluhr R. 2009. Reactive oxygen-generating NAPDH oxidases in plants. In: del Rio LA, Puppo A, eds. Reactive oxygen species in plant signalling. Berlin, Springer-Verlag, 1-23.

Foreman J, Demidchik V, Bothwell JHF, Mylona P, Miedema H, Torres MA, Linstead P, Costa S, Brownlee C, Jones JDG, Davies JM, Dolan L. 2003. Reactive oxygen species produced by NADPH oxidase regulate plant cell growth. Nature 422: 442-446. 
Foyer CH, Noctor G. 2009. Redox regulation in photosynthetic organisms: signaling, acclimation, and practical implications. Antioxidants and Redox Signaling 11: 861-905.

Funck D, Eckard S. Müller G. 2010. Non-redundant functions of two proline dehydrogenase isoforms in Arabidopsis. BMC Plant Biology 10: 70.

Hayashi F, Ichino T, Osanai R, Wada K. 2000. Oscillation and regulation of proline content by P5CS and ProDH gene expressions in the light/dark cycles in Arabidopsis thaliana L. Plant and Cell Physiology 41: 1096-1101.

Hellemans J, Mortier G, De Paepe A, Speleman F, Vandesompele J. 2007. qBase relative quantification framework and software for management and automated analysis of real-time quantitative PCR data. Genome Biology 8: R19.

Hu X, Zhang A, Zheng J, Jiang M. 2006. Abscisic acid is a key inducer of hydrogen peroxide production in leaves of maize plants exposed to water stress. Plant and Cell Physiology 47: 1484-1485.

\section{Jiang C, Belfield EJ, Mithani A, Visscher A, Ragoussis J, Mott R, Smith JAC, Harberd} NP. (2012). ROS-mediated vascular homeostatic control of root-to-shoot soil Na delivery in Arabidopsis. EMBO Journal 31: 4359.

Kiyosue T, Yoshiba Y, Yamaguchi-Shinozaki K, Shinozaki K. 1996. A nuclear gene encoding mitochondrial proline dehydrogenase, an enzyme involved in proline metabolism, is upregulated by proline but downregulated by dehydration in Arabidopsis. Plant Cell 8: 13231335.

Kwak JM, Mori I, Pei Z-M, Leonhardt N, Torres MA, Dangl JL, Bloom R, Bodde S, Jones JDG, Schroeder JI. 2003. NADPH oxidase AtrbohD and AtrbohF genes function in ROS-dependent ABA signaling in Arabidopsis. EMBO Journal 22: 2623-2633.

\section{Leprince AS, Magalhaes N, De Vos D, Bordenave B, Crilat E, Clément G, Meyer C,} Munnik T, Savouré A. 2015. Involvement of Phosphatidylinositol 3-kinase in the regulation of proline catabolism in Arabidopsis thaliana. Frontiers in Plant Science 5: 772-795.

Leshem Y, Seri L, Levine A. 2007. Induction of phosphatidylinositol 3-kinase-mediated endocytosis by salt stress leads to intracellular production of reactive oxygen species and salt tolerance. Plant Journal 51: 185-197.

Ma L, Zhang H, Sun L, Jiao Y, Zhang G, Miao C, Hao F. 2012. NADPH oxidase AtrbohD and AtrbohF function in ROS-dependent regulation of $\mathrm{Na}^{+} / \mathrm{K}^{+}$homeostasis in Arabidopsis under salt stress. Journal of Experimental Botany 63: 305-317. 
Marino D, Dunand C, Puppo A, Pauly N. 2012. A burst of plant NADPH oxidases. Trends in Plant Science 17: 9-15.

Maruta T, Inoue T, Tamoi M, Yabuta Y, Yoshimura K, Ishikawa T, Shigeoka S. 2011. Arabidopsis NADPH oxidases, AtrbohD and AtrbohF, are essential for jasmonic acid-induced expression of genes regulated by MYC2 transcription factor. Plant Science 180: 655-660.

Miller G, Suzuki N, Ciftci-Yilmaz S, Mittler R. 2011. Reactive oxygen species homeostasis and signalling during drought and salinity stresses. Plant Cell and Environment 33: 453-367.

Nakashima K, Ito Y, Yamaguchi-Shinozaki K. 2009. Transcriptional regulatory networks in response to abiotic stresses in Arabidopsis and grasses. Plant Physiology 149: 88-89.

Oracz K, El-Maarouf-Bouteau H, Kranner I, Bogatek R, Corbineau F, Bailly C. 2009. The mechanisms involved in seed dormancy alleviation by hydrogen cyanide unravel the role of reactive oxygen species as key factors of cellular signaling during germination. Plant Physiology 150: 494-505.

Parre E, Ghars MA, Leprince A-S, Thiery L, Lefebvre D, Bordenave M, Luc R, Mazars C, Abdelly C, Savouré A. 2007. Calcium signaling via phospholipase C is essential for proline accumulation upon ionic but not nonionic hyperosmotic stresses in Arabidopsis. Plant Physiology 144: 503-512.

Pellinen R, Palva T, Kangasjärvi J. 1999. Subcellular localization of ozone-induced hydrogen peroxide production in birch (Betula pendula) leaf cells. Plant Journal 20: 349.356. Petrov VD, Van Breusegem F. 2012. Hydrogen peroxide-a central hub for information flow in plant cells. AoB Plant. pls014 doi: 10.1093/aobpla/pls014.

Pogany M, von Rad U, Grun S, Dongo A, Pintye A, Simoneau P, Bahnweg G, Kiss L, Barna B, Durner J. 2009. Dual roles of reactive oxygen species and NADPH oxidase RBOHD in an Arabidopsis-Alternaria pathosystem. Plant Physiology 151: 1459-1475.

Romero-Puertas MC, McCarthy I, Sandalio LM, Palma JM, Corpas FJ, Gomez M, Del Rio LA. 1999. Cadmium toxicity and oxidative metabolism of pea leaves peroxisomes. Free Radical Research 31: 25-31.

Sagi M, Fluhr R. 2001. Superoxide production by plant homologues of the gp $91^{\text {phox }}$ NADPH oxidase. Modulation of activity by calcium and by tobacco mosaic virus infection. Plant Physiology 126: 1281-1290.

Sagi, M, Fluhr, R. (2006). Production of reactive oxygen species by plant NADPH oxidases. Plant Physiology141: 336-340. 
Savouré A, Hua XJ, Bertauche N, Van Montagu M, Verbruggen N. 1997. Abscisic acidindependent and abscisic acid-dependent regulation of proline biosynthesis following cold and osmotic stresses in Arabidopsis thaliana. Molecular and General Genetics 254, 104-109. Savouré A, Jaoua S, Hua XJ, Ardiles W, Van Montagu M, Verbruggen N. 1995. Isolation, characterization, and chromosomal location of a gene encoding the DELTA-1pyrroline-5-carboxylate synthetase in Arabidopsis thaliana. FEBS Letters 372: 13-19.

Servet C, Ghelis T, Richard L, Zilberstein A, Savouré A. 2012. Proline dehydrogenase: a key enzyme in controlling cellular homeostasis. Frontiers in Bioscience 17: 607-620.

Sharma S, Verslues PE. 2010. Mechanisms independent of ABA or proline feedback have a predominant role in transcriptional regulation of proline metabolism during low water potential and stress recovery. Plant Cell and Environment 33: 1838-1851.

Sharma S, Villamor JG, Verslues PE. 2011. Essential role of tissue-specific proline synthesis and catabolism in growth and redox balance at low water potential. Plant Physiology 157: 292-304.

Slama I, Abdelly C, Bouchereau A, Flowers T, Savouré A. 2015. Diversity, distribution and roles of osmoprotective compounds accumulated in halophytes under abiotic stress. Annals of Botany 115: 327-331.

Strizhov N, Abraham E, Okresz L, Blickling S, Zilberstein A, Schell J, Koncz C, Szabados L. 1997. Differential expression of two P5CS genes controlling proline accumulation during salt-stress requires ABA and is regulated by ABA1, ABI1 and AXR2 in Arabidopsis. Plant Journal 12: 557-569.

Szabados L, Savouré A. 2010. Proline: a mulitfunctional amino acid. Trends Plant Science 15: 89-97.

Székely G, Abraham E, Cselo A, Rigo G, Zsigmond L, Csiszar J, Ayaydin F, Strizhov N, Jasik J, Schmelzer E, Koncz C, Szabados L. 2008. Duplicated P5CS genes of Arabidopsis play distinct roles in stress regulation and developmental control of proline biosynthesis. Plant Journal 53: 11-28.

Thiery L, Leprince A-S, Lefebvre D, Ghars MA, Debarbieux E, Savouré A. 2004. Phospholipase D is a negative regulator of proline biosynthesis in Arabidopsis thaliana. Journal of Biological Chemistry 279: 14812-14818.

Torres MA, Dangl JL, Jones JDG. 2002. Arabidopsis gp $91^{\text {phox }}$ homologues AtrbohD and AtrbohF are required for accumulation of reactive oxygen intermediates in the plant defense response. Proceedings of the National Academy of Sciences USA 99: 517-522. 
599 Verbruggen N, Hua XJ, May M, Van Montagu M. 1996. Environmental and

600 developmental signals modulate proline homeostasis: evidence for a negative transcriptional 601 regulator. Proceedings of the National Academy of Sciences USA 93: 8787-8791.

602 Xie YJ, Xu S, Han B, Wu MZ, Yuan XX, Han Y, Gu Q, Xu DK, Yang Q, Shen WB.

603 (2011). Evidence of Arabidopsis salt acclimation induced by up-regulation of HY1 and the 604 regulatory role of RbohD-derived reactive oxygen species synthesis. Plant Journal 66: 280605292.

606 Yang SL, Lan SS, Gong M. 2009. Hydrogen peroxide-induced proline and metabolic 607 pathway of its accumulation in maize seedlings. Journal of Plant Physiology 166: 1694-1699 608 Yoshiba Y, Kiyosue T, Katagiri T, Ueda H, Mizoguchi T, Yamaguchi-Shinozaki K, 609 Wada K, Harada Y, Shinozaki K. 1995. Correlation between the induction of a gene for 610 delta 1-pyrroline-5-carboxylate synthetase and the accumulation of proline in Arabidopsis 611 thaliana under osmotic stress. Plant Journal 7: 751-760.

612 Zhao MG, Chen L, Zhang LL, Zhang WH. 2009. Nitric reductase-dependent nitric oxide 613 production is involved in cold acclimation and freezing tolerance in Arabidopsis. Plant 614 Physiology 151: 755-767. 
616

617

618

619

620

621

622

623

624

625

626

627

628

629

630

631

632

633

634

635

636

637

638

639

640

641

642

643

644

645

646

647

648

\section{Figure legends}

Fig. 1. $\mathrm{NaCl}$ and mannitol stresses trigger transient increases in $\mathrm{H}_{2} \mathrm{O}_{2}$ and proline accumulation.

Twelve-day-old wild-type $A$. thaliana seedlings grown on 0.5 x MS solid medium were transferred to $0.5 \times$ MS liquid medium for treatment. Plants were then exposed to $200 \mathrm{mM}$ $\mathrm{NaCl}$ (triangles), $400 \mathrm{mM}$ mannitol (squares) or neither (circles) for $24 \mathrm{~h}$. Open and closed symbols indicate proline and $\mathrm{H}_{2} \mathrm{O}_{2}$ measurements respectively. The results shown are the means of at least three independent experiments $( \pm \mathrm{SE})$.

Fig. 2. $\mathrm{H}_{2} \mathrm{O}_{2}$ induces proline accumulation.

Proline accumulation in wild-type A. thaliana seedlings treated with $\mathrm{H}_{2} \mathrm{O}_{2}$ (a) and paraquat (b) for $24 \mathrm{~h}$. Means ( $\pm \mathrm{SE}$ ) of at least three independent experiments with different letters are significantly different at $P<0.05$. (c) $\mathrm{H}_{2} \mathrm{O}_{2}$ was visualized by using DAB staining in $A$. thaliana leaves exposed to different concentrations of paraquat for $24 \mathrm{~h}$.

Fig. 3. The NADPH oxidase inhibitor DPI and the $\mathrm{H}_{2} \mathrm{O}_{2}$ scavenger DMTU affect proline accumulation induced by salt or mannitol stress.

Twelve-day-old $A$. thaliana seedlings grown on $0.5 \times$ MS solid medium were transferred to $0.5 \times$ MS liquid medium for treatment. Plants were preincubated with various concentrations of DMTU (a) or DPI (b) for $4 \mathrm{~h}$ and then exposed to $200 \mathrm{mM} \mathrm{NaCl}$ (grey bars), $400 \mathrm{mM}$ mannitol (black bars) or neither (white bars) for $24 \mathrm{~h}$. Means ( \pm SE) of three independent experiments with different letters are significantly different at $P<0.05$.

Fig. 4. $\mathrm{NaCl}$ and mannitol stresses trigger apoplastic $\mathrm{H}_{2} \mathrm{O}_{2}$ accumulation in A. thaliana leaves.

Twelve-day-old seedlings grown on $0.5 \times$ MS solid medium were transferred to $0.5 \times$ MS liquid medium. Subcellular localization of $\mathrm{H}_{2} \mathrm{O}_{2}$ was detected by $\mathrm{CeCl}_{3}$ staining of leaves of wild-type A. thaliana grown under normal conditions (control, a, d) or in the presence of either $200 \mathrm{mM} \mathrm{NaCl}$ (b, e) or $400 \mathrm{mM}$ mannitol (c, f) for $6 \mathrm{~h}$. Arrows indicate electron-dense deposits of cerium perhydroxides formed in the presence of $\mathrm{H}_{2} \mathrm{O}_{2}$ and $\mathrm{CeCl}_{3}$. Ch, chloroplast; CW, cell wall; M, mitochondria; S, starch; V, vacuole.

Fig. 5. Inhibition of proline accumulation by DPI can be reversed. 
649

650

651

652

653

654

655

656

657

658

659

660

661

662

663

664

665

666

667

668

669

670

671

672

673

674

675

676

677

678

679

680

A. thaliana seedlings were pre-treated with $20 \mu \mathrm{M}$ DPI as described in the legend of Fig. 3 and then treated with either $200 \mathrm{mM} \mathrm{NaCl}$ or $400 \mathrm{mM}$ mannitol for $24 \mathrm{~h} \mathrm{(a)}$. Seedlings were then washed twice and transferred onto $\mathrm{NaCl}$ or mannitol medium for another $24 \mathrm{~h}$ (b). Means $( \pm \mathrm{SE}$ ) of three independent experiments with different letters are significantly different at $P<$ 0.05 .

Fig. 6. DPI inhibition of NADPH oxidase activity affects proline metabolism induced by either salt or osmotic stress.

A. thaliana seedlings were prepared and treated as previously described in the legend of Fig. 3. (a) Sites of $\mathrm{H}_{2} \mathrm{O}_{2}$ production visualized by using 2',7'-dichlorofluorescein diacetate ( $\mathrm{H}_{2}$ DCFDA) in wild-type $A$. thaliana root tips pre-treated with $20 \mu \mathrm{M}$ DPI and grown under normal conditions or in the presence of either $200 \mathrm{mM} \mathrm{NaCl}$ or $400 \mathrm{mM}$ mannitol for $6 \mathrm{~h}$. (b) Proline accumulation in wild-type seedlings pre-treated with $20 \mu \mathrm{M}$ DPI and grown under normal conditions or in the presence of either $200 \mathrm{mM} \mathrm{NaCl}$ or $400 \mathrm{mM}$ mannitol for $24 \mathrm{~h}$. Means $( \pm$ SE) of three independent experiments with different letters are significantly different at $P<0.05$. (c) RT-PCR analysis of P5CS1 and ProDH1 expression. RT-PCR was performed using total RNAs extracted from seedlings treated for $24 \mathrm{~h}$ as described in (b). APT1 transcripts were amplified as an internal control. Lower panels, quantification of the expression of P5CS1 and ProDH1 normalized to APT1. (d) Western blot of P5CS and ProDH proteins from seedlings treated for $24 \mathrm{~h}$ as described in (b). Rubisco revealed by Ponceau-S staining of all protein was used as a loading control.

Fig. 7. AtRbohD and AtRbohF are required for transient $\mathrm{H}_{2} \mathrm{O}_{2}$ accumulation induced by salt or mannitol stress.

A. thaliana seedlings were prepared and treated as described in the legend of Fig. $3 . \mathrm{H}_{2} \mathrm{O}_{2}$ accumulation was measured in seedlings of wild-type and the transposon insertion mutants atrbohd-3 and atrbohf-3 at $6 \mathrm{~h}$ after stress treatment with either $200 \mathrm{mM} \mathrm{NaCl}$ or $400 \mathrm{mM}$ mannitol. Means ( \pm SE) of three independent experiments with different letters are significantly different at $P<0.05$.

Fig. 8. AtRbohD and AtRbohF are essential for proline accumulation in response to either $\mathrm{NaCl}$ or mannitol. 
681

682

683

684

685

686

687

688

689

690

691

692

693

694

695

696

697

698

699

700

701

702

703

704

705

706

A. thaliana seedlings were prepared and treated as previously described in the legend of Fig. 3. (a) Proline accumulation was determined in transposon insertion mutant lines atrbohd-3, atrbohf-3 single mutants and in atrbohd/f double mutant in comparison to wild-type grown under normal conditions or in the presence of either $200 \mathrm{mM} \mathrm{NaCl}$ or $400 \mathrm{mM}$ mannitol for $24 \mathrm{~h}$. Proline content was also measured in wild type and mutant seedlings grown in the same condition after application of $10 \mathrm{mM} \mathrm{H}_{2} \mathrm{O}_{2}$. Means ( $\pm \mathrm{SE}$ ) of three biological replicates with different letters were significantly different at $P<0.05$. (b) Western blot of P5CS proteins from seedlings treated as described in (a). Rubisco revealed by Ponceau-S staining of all proteins was used as loading control. Quantification of the western blot normalized to Rubisco is shown as bar graph. C, control; N, NaCl; M, mannitol.

\section{Supporting Information}

Fig. S1. Early apoplastic $\mathrm{H}_{2} \mathrm{O}_{2}$ accumulation is mediated through plasma membrane-bound NADPH oxidases in leaves of $A$. thaliana in response to either $\mathrm{NaCl}$ or mannitol.

Fig. S2. Proline accumulation in atrboh insertion lines.

Fig. S3. qRT-PCR analysis of differential expression of three AtRboh genes in wild-type and atrbohd and atrbohf mutants.

Fig. S4. Changes in $\mathrm{Na}^{+}$and $\mathrm{K}^{+}$content and $\mathrm{Na}^{+} / \mathrm{K}^{+}$ratios in Arabidopsis wild-type (WT) and atrbohd and atrbohf mutants upon $\mathrm{NaCl}$ stress.

Table S1: List of primers used for RT-PCR and qRT-PCR analysis. 


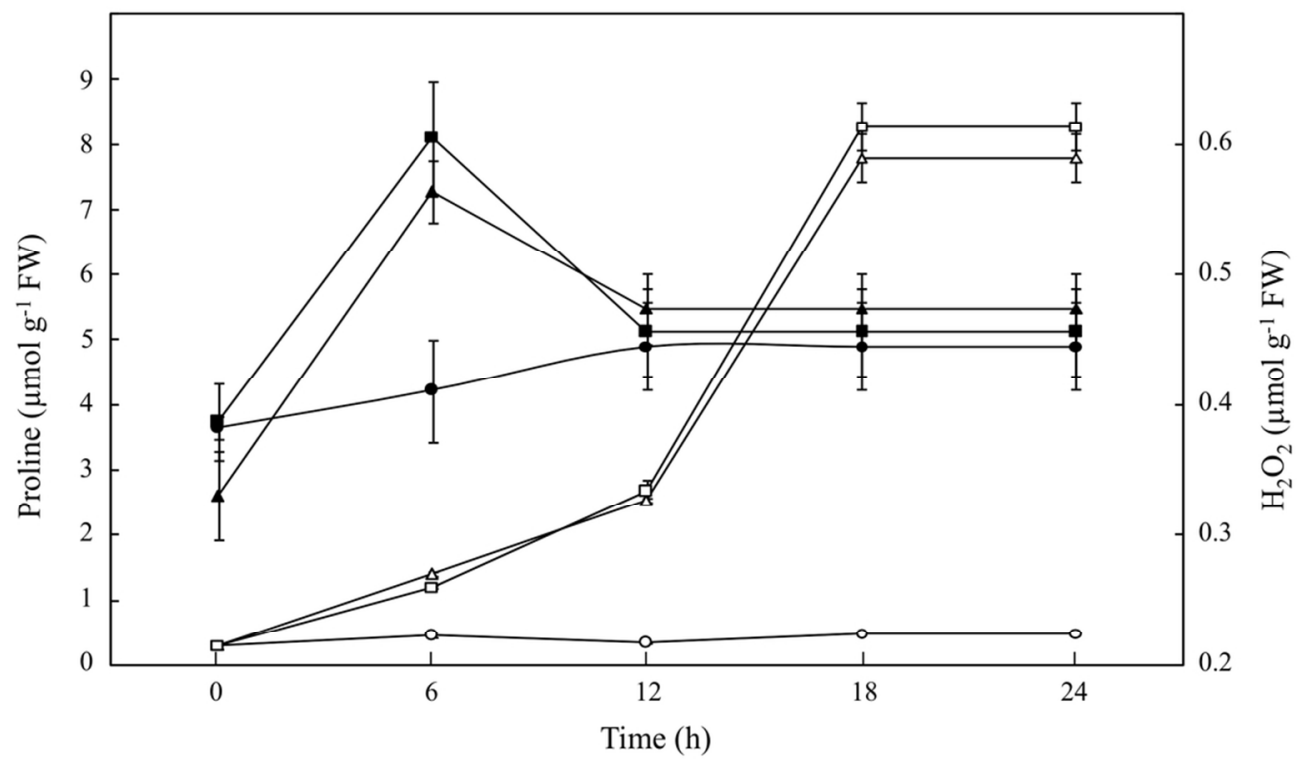

Fig. 1. $\mathrm{NaCl}$ and mannitol stresses trigger transient increases in $\mathrm{H} 2 \mathrm{O} 2$ and proline accumulation. Twelve-day-old wild-type A. thaliana seedlings grown on $0.5 \times$ MS solid medium were transferred to $0.5 \times$ MS liquid medium for treatment. Plants were then exposed to $200 \mathrm{mM} \mathrm{NaCl}$ (triangles), $400 \mathrm{mM}$ mannitol (squares) or neither (circles) for $24 \mathrm{~h}$. The results shown are the means of at least three independent experiments $( \pm \mathrm{SE})$.

$46 \times 27 \mathrm{~mm}(600 \times 600 \mathrm{DPI})$ 

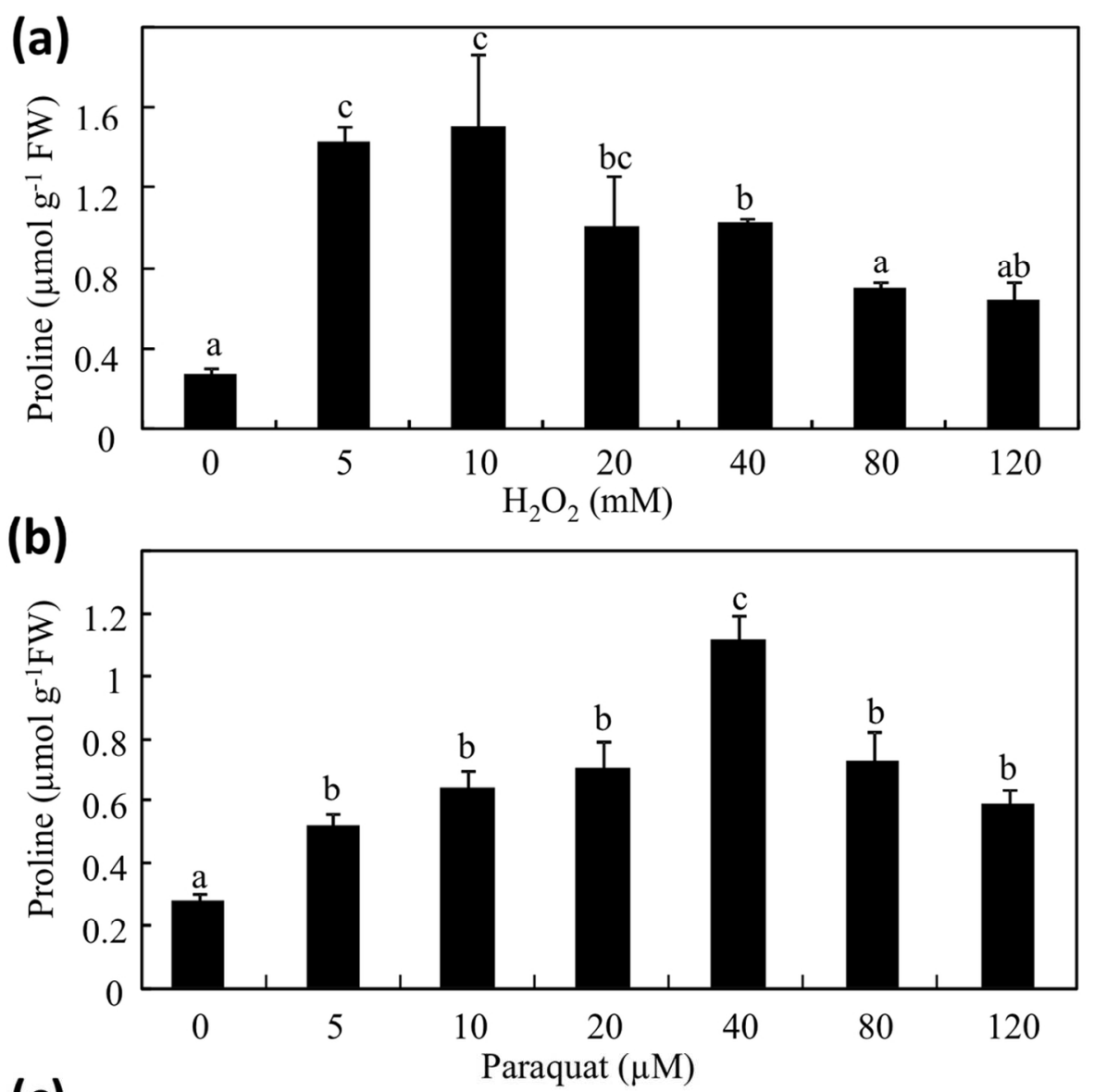

(c)

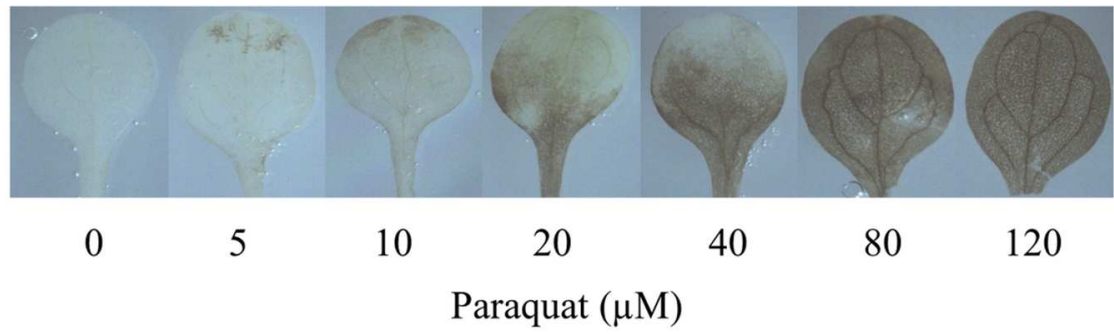

Fig.2. $\mathrm{H} 2 \mathrm{O} 2$ induces proline accumulation.

Proline accumulation in wild-type A. thaliana seedlings treated with $\mathrm{H} 2 \mathrm{O} 2$ (a) and paraquat (b) for $24 \mathrm{~h}$. Means ( \pm SE) of at least three independent experiments with different letters are significantly different at $P$ $<0.05$. (c) $\mathrm{H} 2 \mathrm{O} 2$ was visualized by using DAB staining in A. thaliana leaves exposed to different concentrations of paraquat for $24 \mathrm{~h}$.

$102 \times 130 \mathrm{~mm}(300 \times 300 \mathrm{DPI})$ 
(a)

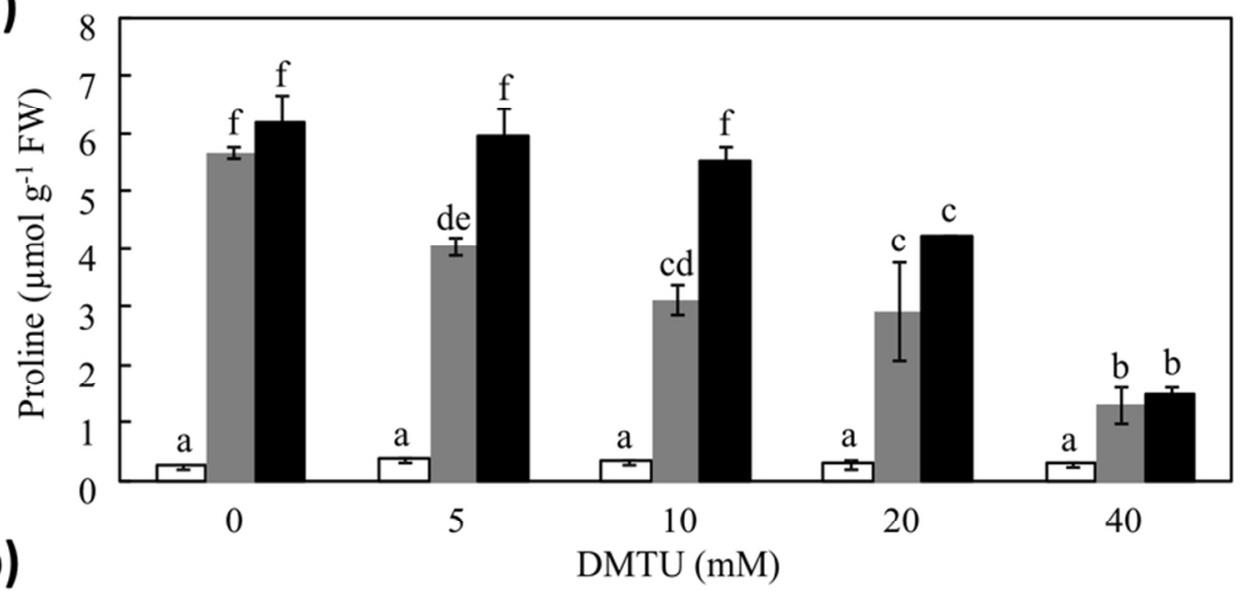

(b)

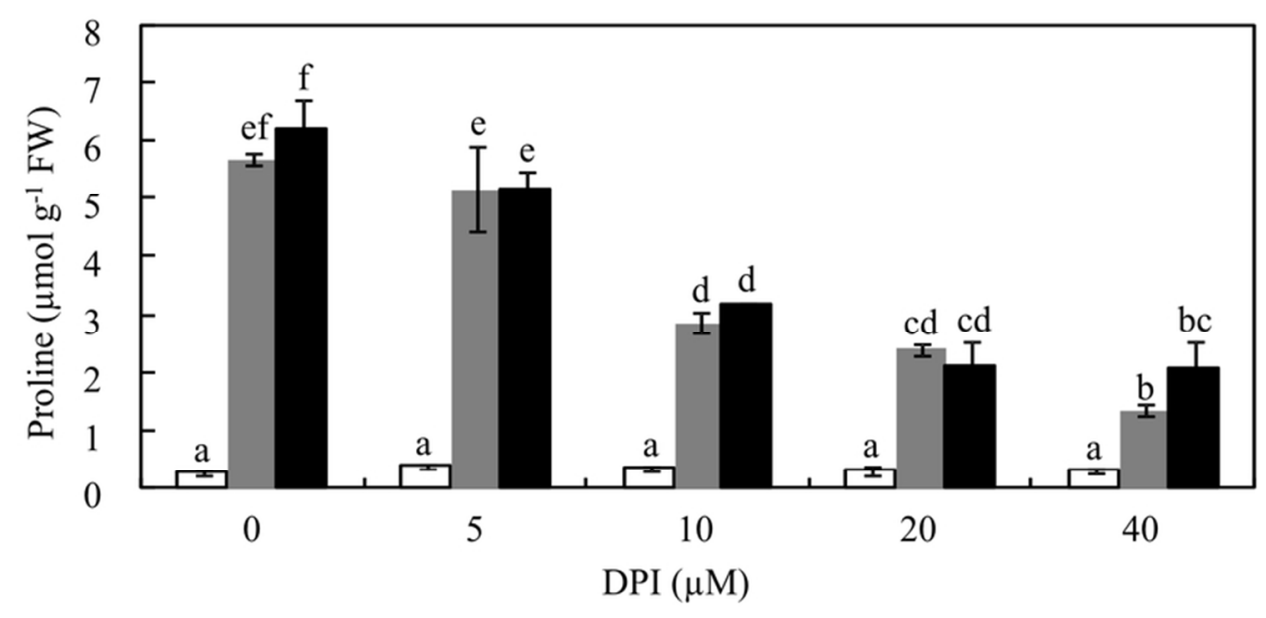

Fig. 3. The NADPH oxidase inhibitor DPI and the H2O2 scavenger DMTU affect proline accumulation induced by salt or mannitol stress.

Twelve-day-old A. thaliana seedlings grown on $0.5 \times$ MS solid medium were transferred to $0.5 \times$ MS liquid medium for treatment. Plants were preincubated with various concentrations of DMTU or DPI for $4 \mathrm{~h}$ and then exposed to $200 \mathrm{mM} \mathrm{NaCl}$ (grey bars), $400 \mathrm{mM}$ mannitol (black bars) or neither (white bars) for $24 \mathrm{~h}$. Means $( \pm$ SE) of three independent experiments with different letters are significantly different at $P<0.05$.

$76 \times 72 \mathrm{~mm}(300 \times 300$ DPI $)$ 


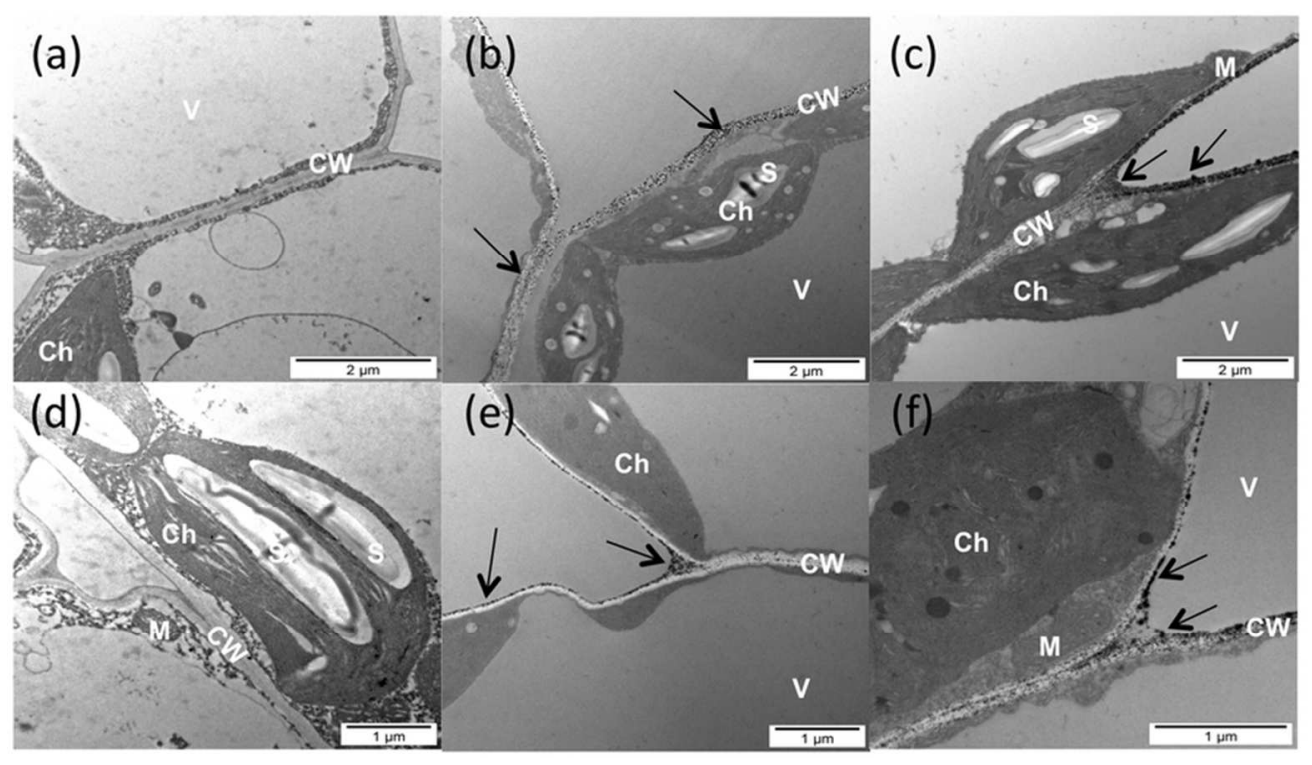

Fig. 4. $\mathrm{NaCl}$ and mannitol stresses trigger apoplastic $\mathrm{H} 2 \mathrm{O} 2$ accumulation in $\mathrm{A}$. thaliana leaves.

Twelve-day-old seedlings grown on $0.5 \times$ MS solid medium were transferred to $0.5 \times$ MS liquid medium. Subcellular localization of $\mathrm{H} 2 \mathrm{O} 2$ was detected by $\mathrm{CeCl} 3$ staining of leaves of wild-type A. thaliana grown under normal conditions (control, $a, d$ ) or in the presence of either $200 \mathrm{mM} \mathrm{NaCl}(b, e)$ or $400 \mathrm{mM}$ mannitol $(\mathrm{c}, \mathrm{f})$ for $6 \mathrm{~h}$. Arrows indicate electron-dense deposits of cerium perhydroxides formed in the presence of $\mathrm{H} 2 \mathrm{O} 2$ and $\mathrm{CeCl} 3$. Ch, chloroplast; CW, cell wall; M, mitochondria; S, starch; V, vacuole.

$75 \times 43 \mathrm{~mm}(300 \times 300$ DPI $)$ 


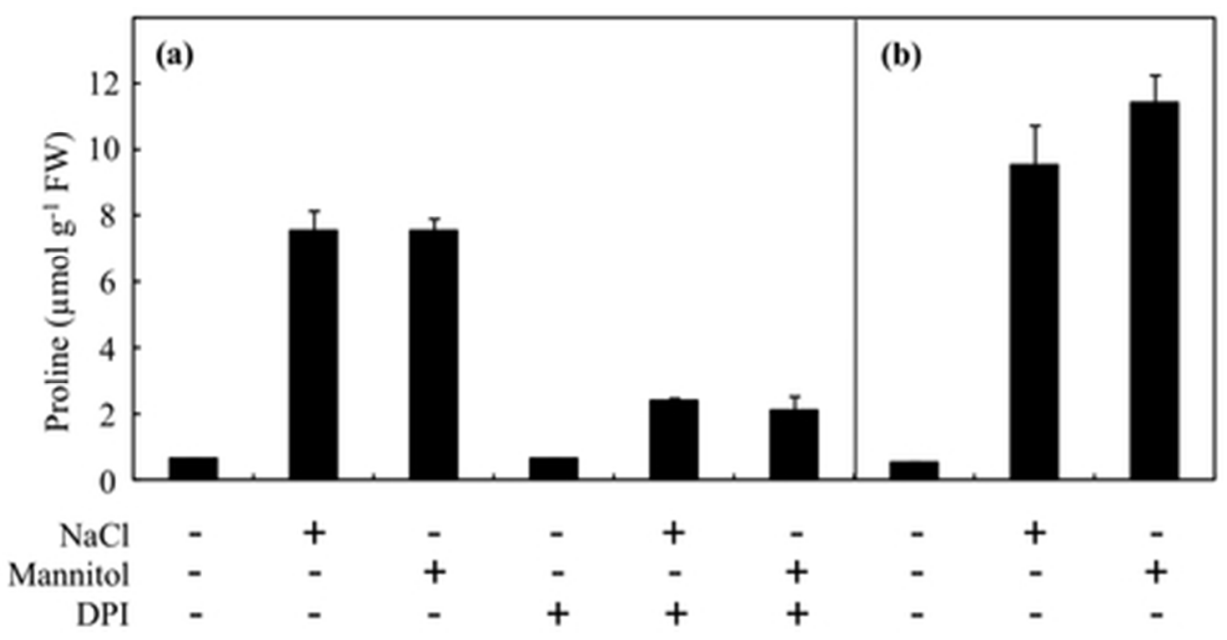

Fig. 5. Inhibition of proline accumulation by DPI can be reversed.

A. thaliana seedlings were pre-treated with $20 \mu \mathrm{M}$ DPI as described in the legend of Fig. 3 and then treated with either $200 \mathrm{mM} \mathrm{NaCl}$ or $400 \mathrm{mM}$ mannitol for $24 \mathrm{~h} \mathrm{(a).} \mathrm{Seedlings} \mathrm{were} \mathrm{then} \mathrm{washed} \mathrm{twice} \mathrm{and}$ transferred onto $\mathrm{NaCl}$ or mannitol medium for another $24 \mathrm{~h}$ (b). Means ( $\pm \mathrm{SE}$ ) of three independent experiments with different letters are significantly different at $\mathrm{P}<0.05$.

$40 \times 20 \mathrm{~mm}(300 \times 300$ DPI $)$ 
(a)

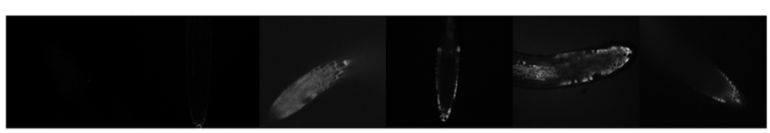

(b)

(c)
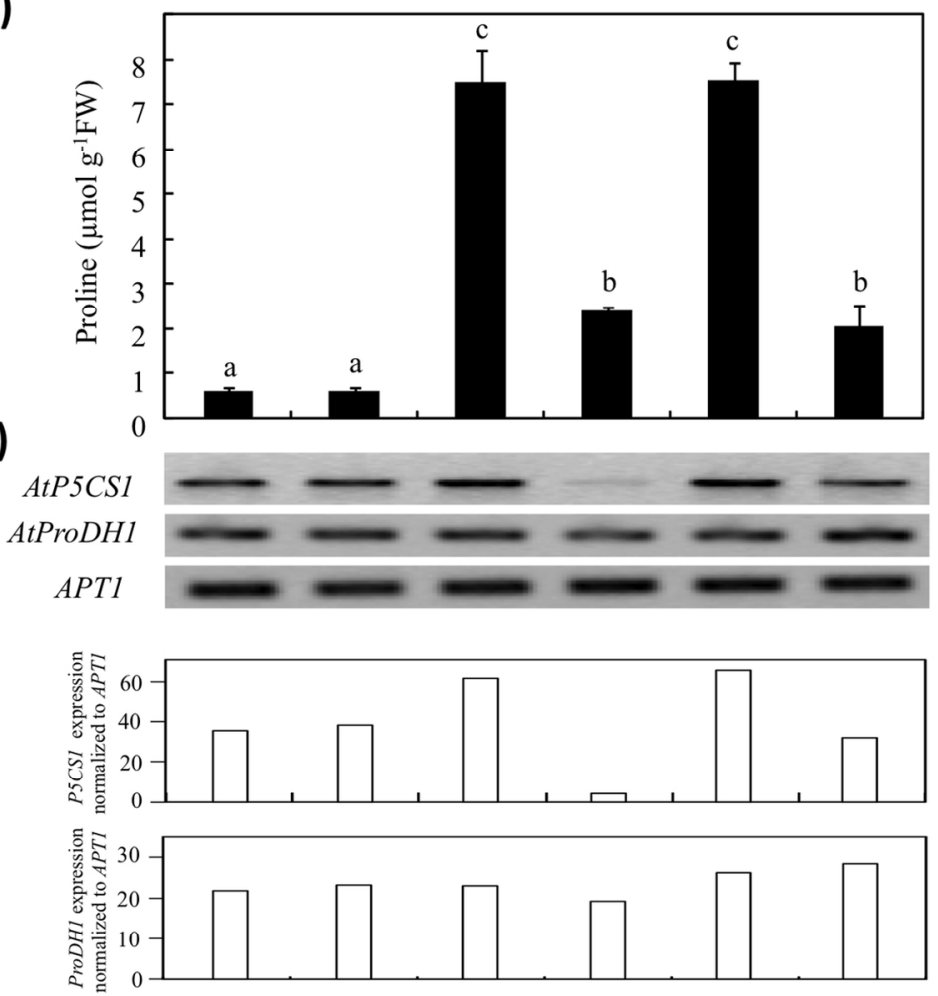

(d)

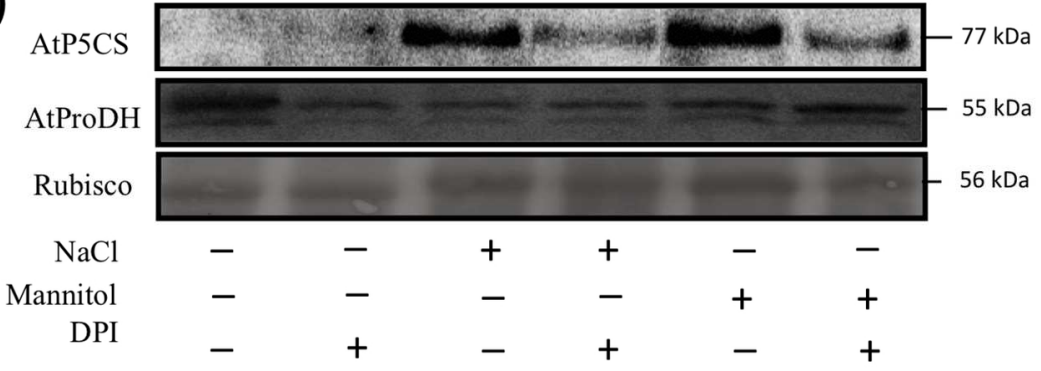

Fig. 6. DPI inhibition of NADPH oxidase activity affects proline metabolism induced by either salt or osmotic stress.

A. thaliana seedlings were prepared and treated as previously described in the legend of Fig. 3. (a) Sites of $\mathrm{H} 2 \mathrm{O} 2$ production visualized by using $2^{\prime}, 7^{\prime}$-dichlorofluorescein diacetate (H2DCFDA) in wild-type A. thaliana root tips pre-treated with $20 \mu \mathrm{M}$ DPI and grown under normal conditions or in the presence of either 200 $\mathrm{mM} \mathrm{NaCl}$ or $400 \mathrm{mM}$ mannitol for $6 \mathrm{~h}$. (b) Proline accumulation in wild-type seedlings pre-treated with 20 $\mu \mathrm{M}$ DPI and grown under normal conditions or in the presence of either $200 \mathrm{mM} \mathrm{NaCl}$ or $400 \mathrm{mM}$ mannitol for $24 \mathrm{~h}$. Means ( \pm SE) of three independent experiments with different letters are significantly different at $\mathrm{P}$ $<0.05$. (c) RT-PCR analysis of P5CS1 and ProDH1 expression. RT-PCR was performed using total RNAs extracted from seedlings treated for $24 \mathrm{~h}$ as described in (b). APT1 transcripts were amplified as an internal control. Lower panels, quantification of the expression of P5CS1 and ProDH1 normalized to APT1. (d) Western blot of P5CS and ProDH proteins from seedlings treated for $24 \mathrm{~h}$ as described in (b). Rubisco revealed by Ponceau-S staining of all protein was used as a loading control. 


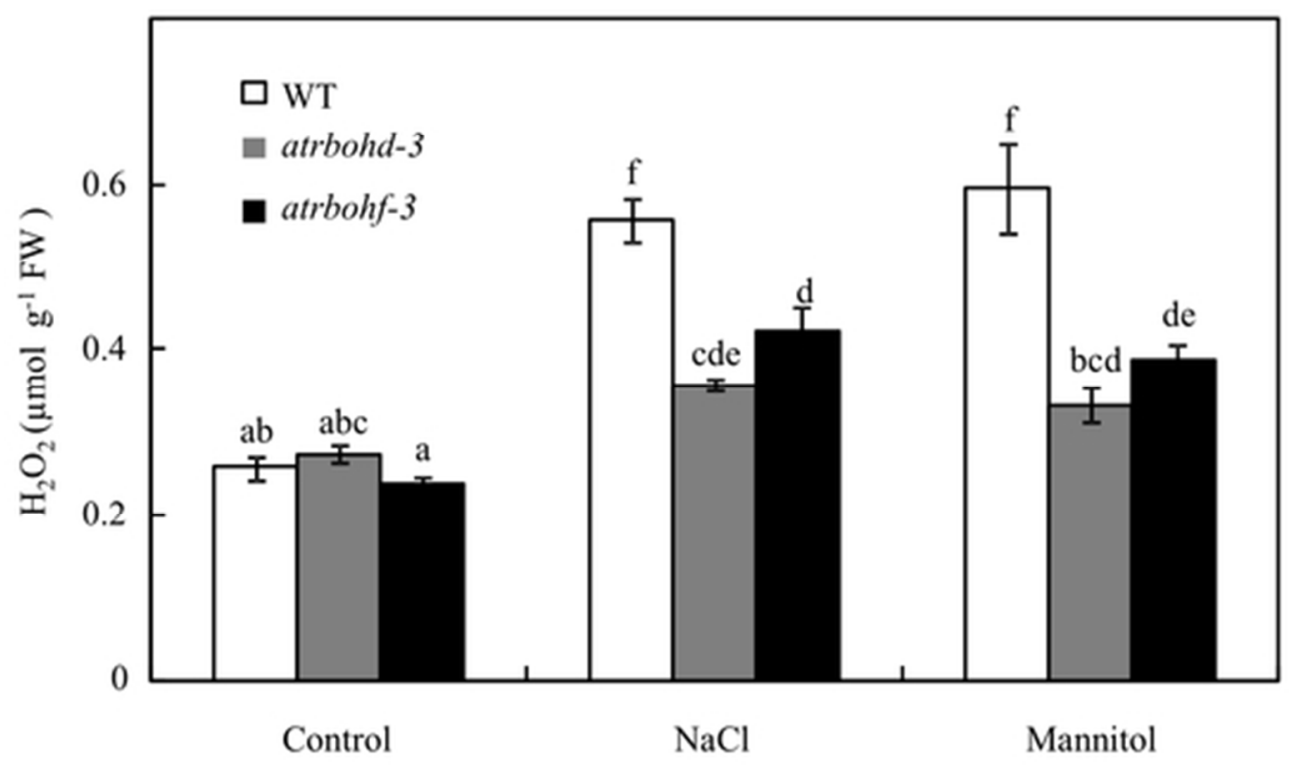

Fig. 7. AtRbohD and AtRbohF are required for transient $\mathrm{H} 2 \mathrm{O} 2$ accumulation induced by salt or mannitol stress.

A. thaliana seedlings were prepared and treated as described in the legend of Fig. 3. H2O2 accumulation was measured in seedlings of wild-type and the transposon insertion mutants atrbohd- 3 and atrbohf- 3 at 6 $\mathrm{h}$ after stress treatment with either $200 \mathrm{mM} \mathrm{NaCl}$ or $400 \mathrm{mM}$ mannitol. Means ( $\pm \mathrm{SE}$ ) of three independent experiments with different letters are significantly different at $P<0.05$.

$$
46 \times 26 \mathrm{~mm}(300 \times 300 \text { DPI })
$$


(a)
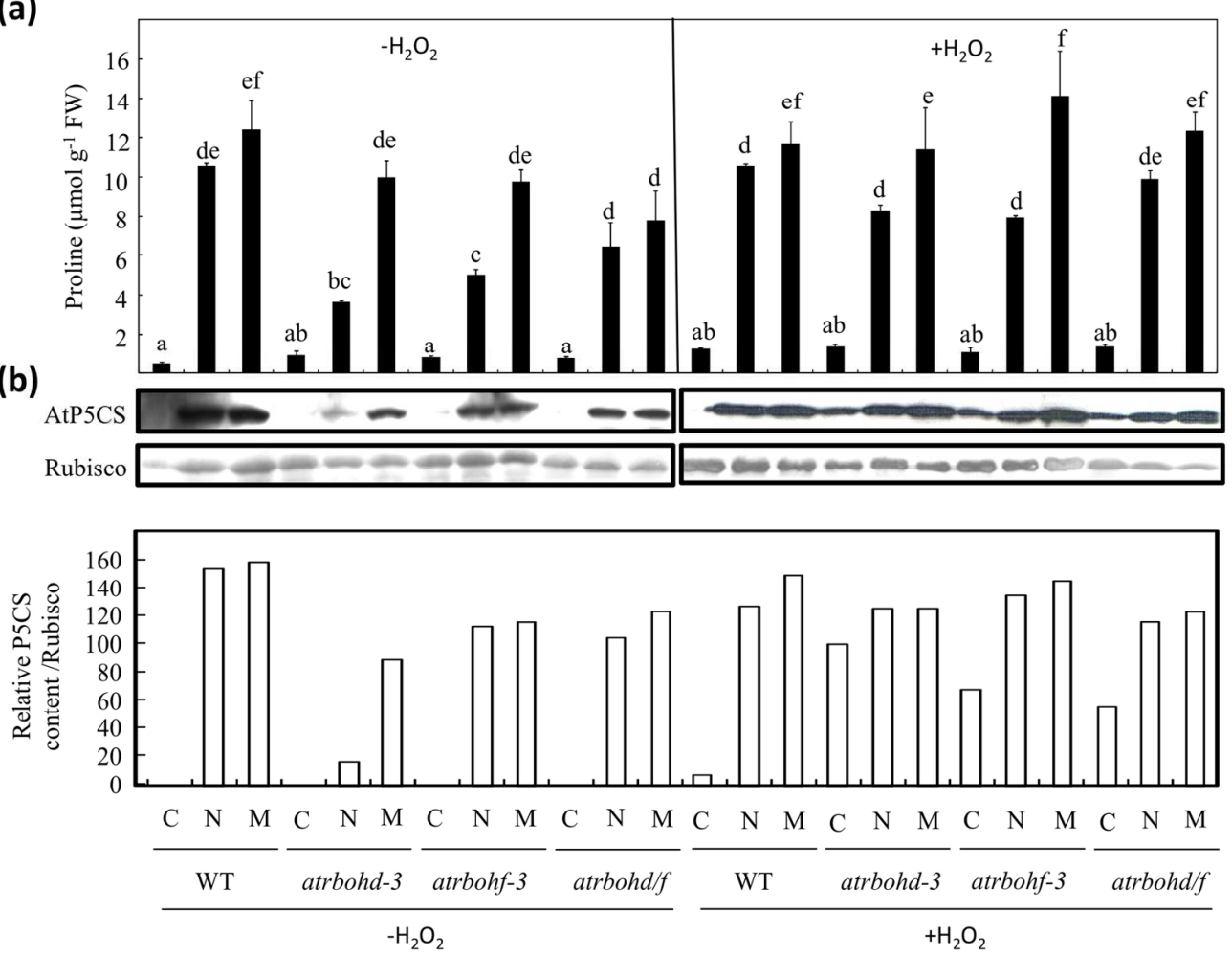

Fig. 8. AtRbohD and AtRbohF are essential for proline accumulation in response to either $\mathrm{NaCl}$ or mannitol. A. thaliana seedlings were prepared and treated as previously described in the legend of Fig. 3. (a) Proline accumulation was determined in transposon insertion mutant lines atrbohd-3, atrbohf-3 single mutants and in atrbohd/f double mutant in comparison to wild-type grown under normal conditions or in the presence of either $200 \mathrm{mM} \mathrm{NaCl}$ or $400 \mathrm{mM}$ mannitol for $24 \mathrm{~h}$. Proline content was also measured in wild type and mutant seedlings grown in the same condition after application of $10 \mathrm{mM} \mathrm{H} 2 \mathrm{O} 2$. Means ( $\pm \mathrm{SE}$ ) of three biological replicates with different letters were significantly different at $P<0.05$. (b) Western blot of P5CS proteins from seedlings treated as described in (a). Rubisco revealed by Ponceau-S staining of all proteins was used as loading control. Quantification of the western blot normalized to Rubisco is shown as bar graph. C, control; $\mathrm{N}, \mathrm{NaCl} ; \mathrm{M}$, mannitol.

$78 \times 60 \mathrm{~mm}(600 \times 600 \mathrm{DPI})$ 